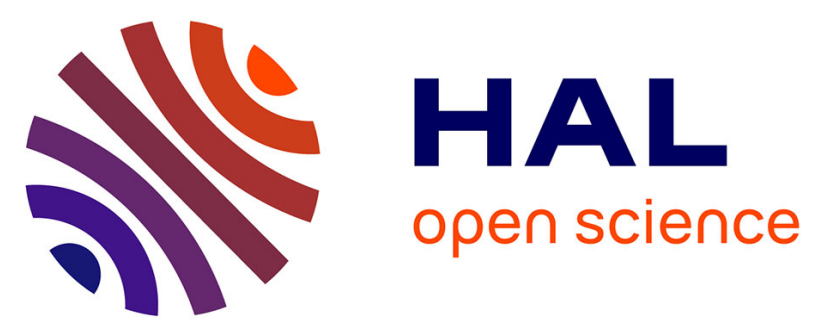

\title{
Transcription systems for sign languages: a sketch of the different graphical representations of sign language and their characteristics
}

Brigitte Garcia, Marie-Anne Sallandre

\section{- To cite this version:}

Brigitte Garcia, Marie-Anne Sallandre. Transcription systems for sign languages: a sketch of the different graphical representations of sign language and their characteristics. C. Müller, A. Cienki, E. Fricke, S. Ladewig, D. McNeill and S. Tessendorf. Handbook "Body-Language-Communication", Mouton De Gruyter, pp.1125-1338, 2013. hal-01043755

HAL Id: hal-01043755

https://hal-univ-paris8.archives-ouvertes.fr/hal-01043755

Submitted on 23 Jul 2014

HAL is a multi-disciplinary open access archive for the deposit and dissemination of scientific research documents, whether they are published or not. The documents may come from teaching and research institutions in France or abroad, or from public or private research centers.
L'archive ouverte pluridisciplinaire HAL, est destinée au dépôt et à la diffusion de documents scientifiques de niveau recherche, publiés ou non, émanant des établissements d'enseignement et de recherche français ou étrangers, des laboratoires publics ou privés. 


\title{
72. Transcription systems for sign languages: A sketch of the different graphical representations of sign language and their characteristics
}

1. Socio-historical and structural features of sign languages

2. Notation systems

3. Annotation systems

4. Problems and perspectives

5. References

\begin{abstract}
Sign languages are natural languages developed and used in all parts of the world where there are deaf people. Although different from each other, these languages, that have been exposed to varying degrees of communitisation and institutionalisation, share a signifcant number of common structures. As in the study of any other language, the linguistic study of visual-gestural languages, now a scientific field in its own right, faces the unavoidable problem of their graphical representation. This paper provides an overview, albeit non-exhaustive, of existing solutions to this challenge.We begin by reviewing the main difficulties posed by the graphical representation of these languages, which have no writing system of their own, taking into consideration their modal and structural characteristics (section 2). We then present the major types of graphical representations that have been developed for sign languages, noting their respective strengths and limitations (sections 3 and 4). In section 5, we outline the problems that remain unsolved at this point, if one aims to achieve transcription of a growing number of sign language corpora that would meet research needs while respecting the original features particular to these languages.
\end{abstract}

\section{Socio-historical and structural features of sign languages}

In the course of history, the existence of signing deaf communities is attested in various sources (e.g.Saint-Augustin2002 [De Magistro]; Montaigne 2009 [Essais, II.12]). And AQ336 yet, sign languages have been virtually ignored as such, until very recently. While the idea of the educability of the deaf emerged in the Renaissance, sign languages acquired real visibility only with the educational enterprise initiated in 1760 by Abbé CharlesMichel de l'Epée (1712-1789). Introducing the revolutionary principle of mass education of the deaf based on their "mimicry," de L'Epée gave a social existence to the deaf and their language, which lasted a little over a century. However, this initial phase of recognition was followed by a new century of denial, starting with the prohibition of sign languages in the Congress of Milan (1880) and until the deaf awakening in 1960-1980. Sign language linguistics itself is still a young domain, initiated in the 20th century by Stokoe's (1960) study of American Sign Language (ASL), and becoming an active and diverse theoretical field since.

Given that the deaf (always a minority) have been socially recognised as speakers only during brief periods, it is hardly surprising that no sign language has developed 
a writing system. The vast majority of spoken languages are also unwritten. The major difference, however, is that some writing system can be easily adapted for use in any spoken language over time. No such option exists for sign language, which has no similar written tradition to build upon. In light of the writing processes used in spoken languages, sign languages pose very specific problems, related to their modality and its structural consequences.

Crucially, sign languages exploit the availability of all manual and bodily articulators (hands, head, shoulders, facial expressions, eye gaze), which can be used simultaneously or in succession. This parametric multi-linearity is combined with a sophisticated use of the space in front of the signer that is opened by these articulators; thus, most syntactico-semantic relations in sign languages are spatialised (establishment of reference to entities, time and space, pronominalisation and maintained reference). It is agreed that these characteristics reflect the difficulties raised by the graphical representation of these languages: complex temporal relations between the articulators (co-articulation, hold and overlap), appropriate use of space through pointing signs and continued use of the areas thus activated, variability of gestural units through the modification of location and/or orientation (e.g., Bergman et al. 2001; Johnston 1991; Miller 1994; AQ337 Stokoe 1987). However, the descriptive approach proposed by the semiological model (Cuxac 1996, 2000) points to an additional difficulty.

In addition to conventional lexical units that are widely recognized in the literature (as "frozen signs" or even "signs" or "words"), this model considers as central another type of unit, non-conventionalised but employing a limited number of structures (termed transfer units). Although listed in the literature as "classifier constructions" (see Emmorey 2003) or "productive signs" (Brennan 1990), these units are generally analyzed as peripheral and non-linguistic. Yet, they represent $30-80 \%$ of sign language discourse (Sallandre 2003; Antinoro Pizzuto et al. 2008). If we adopt the semiological perspective that considers units of this type the very heart of sign languages, their inclusion increases the difficulty of graphical representation, as they are based on a semiosis of the continuity, given their "illustrative intent" to say through showing. In sign language discourse, these units are tightly intertwined with the conventional units ("non-illustrative intent"), and the entire discourse alternates between both intents.

Significantly, the two moments in history which gave rise to an explicit linguistic reflection on sign languages were accompanied by the development of graphical systems for their representation: Bébian (1825) and Stokoe (1960). The development of the modern linguistic study of these languages has also been accompanied by a proliferation of graphical systems (for a review, see Boutora 2005). Classification of these inventions must take two variables into account. First, the goals of the representation system, as transcription only (the graphic representation of produced data) or as a system for written communication as well. Second, and more importantly, the semiological features of the system used, in particular whether it employs specific symbols and its own internal logic, or a pre-existing writing system (de facto, the written form of the national spoken language). On this basis, we can distinguish two sets, which we term "notation systems" and "annotation systems." Notation systems are autonomous and specific systems, sometimes intended for written communication, which share central semiological features: They are mono-linear, and focused, at least in their design, on the representation of lexical signs in terms of their visual form outside any discourse context. In contrast, annotation systems, which are based on the written form of spoken 
language, are intended to represent discourse, and used only in the context of linguistic research.

\section{Notation systems}

The moment sign language was taken into consideration in the education of deaf children, its graphical representation became an issue, particularly for the creation of dictionaries for teachers and students. We will not specify the graphical means used in such dictionaries from the late 18th century, referring the reader to the full review by Bonnal (2005). Two methods (which may be combined) were used for these representations: drawing (enhanced by symbols indicating movement, at times represented by a sequence of drawings) and, the more dominant, descriptions of the signifier form of a sign, written in spoken language.

The first independent notation system is Bébian's (1825) Mimographie, developed for the sign language used at the Institution de Paris, and intended for purely pedagogical purposes (e.g. Fischer 1995). Bébian's aim was not to provide a written form of signed discourse, but simply to represent the "mimicked signs." This purpose is remarkably ahead of its time. The idea is that each sign is represented in a linear sequence indicating the relevant body part ("l'organe qui agit," represented through 86 characters), its movement (68), its position (14), and if needed, the facial expression (20) as well. The Mimographie system, although never implemented and not the only attempt at notation in the 19th century (Piroux 1830), is foundational, and serves as the basis for all modern notation systems, starting with Stokoe (1960).

For Stokoe (1960, [1965] 1976), the creation of notation rather than transcription was AQ338 seen as part of the demonstration of the linguistic status of American Sign Language, the characters, cherems, intended to be equivalent to phonemes, and thus to prove the existence of a double articulation. His analysis of signs is directly inspired by Bébian but diverges in several respects. Focusing only on manual aspects, Stokoe retains only the handshape (vs. Bébian's conformation, which included orientation as well), and adding the parameter of location, but removes facial expression. Stokoe's system is composed of 55 cherems (19 handshapes, 12 locations, 24 movements), using symbols borrowed from the Latin alphabet, the numerical system and some invented for this purpose, and is generally devoid of iconicity. This model is the direct source of the vast majority of systems used over the next two decades, as linguistic study of other sign languages developed, now focusing on transcription.

\section{$6 V_{0}^{11}$}

Fig. 72.1: Notation in Stokoe's (1960) system: The sign [SNAKE] in American Sign Language (Martin 2000).

\subsection{Notation for transcription}

Miller (2001: 13-16) provides a detailed genealogy of the major systems derived from AQ340 Stokoe's (see http://sign.let.ru.nl/groups/slcwikigroup/wiki/c6573/). Variations between 
them typically stem from theoretical developments (generative and post-generative phonology), the addition of the "orientation" parameter (following Battison 1973), the adaptation to different sign languages and options for the parametric linear sequencing of symbols. However, each system is only comprehensible to the research team using it.

One noteworthy system based on Stokoe's is the HamNoSys, developed in Hamburg (Prillwitz et al. 1989). HamNoSys is intended to enable the phonetic transcription of all sign languages, and therefore includes a considerable number of symbols (more than 200 basic symbols), and gradually enhanced for the notation of spatial cues and nonmanual aspects (facial expression, body movements, prosody, eye gaze). Unlike Stokoe's system, HamNoSys employs iconic symbols and shows strong internal systematicity. Yet, it faces a serious legibility problem, particularly for the recording of discourse. Nevertheless, thanks to its fast digitization and compatibility with annotation software (see 3.2 below), it is integrated in large lexical databases (Ilex, Hanke and Storz 2008; Auslan Database, Johnston 1991-2011), and is a notation system which has been frequently used in sign language research.

\begin{tabular}{|c|c|}
\hline 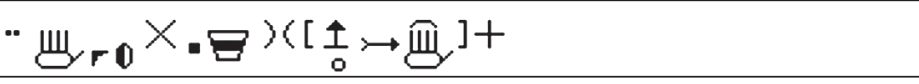 & bears \\
\hline 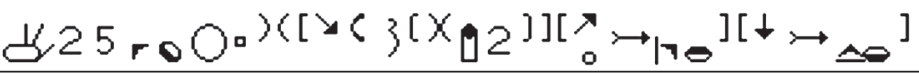 & Goldilocks \\
\hline 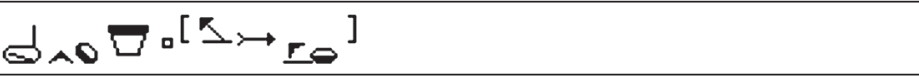 & $\begin{array}{l}\text { somewhere } \\
\text { wandering }\end{array}$ \\
\hline 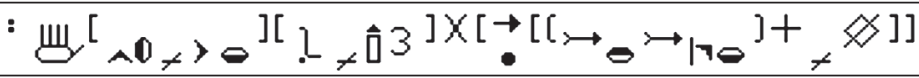 & deep forest \\
\hline 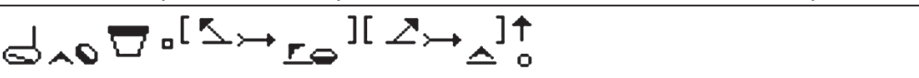 & $\begin{array}{l}\text { somewhere } \\
\text { wandering }\end{array}$ \\
\hline
\end{tabular}

Fig. 72.2: Notation in HamNoSys (Bentele 1999)

Whatever their respective contributions, there is general agreement that these various systems have some limitations. The most notable is their virtual inability to represent discourse sequences and taking note of constituent principles. Their inherent monolinearity prevents a readable representation of the spatio-temporal relations that are essential for sign language syntax. In addition, these systems were established solely on the analysis of decontextualised manual signs, abstracting away from their use in discourse (modifications of internal parameters, discursive framing of the conventional sign by non manual components).

\subsection{Notation for transcription and written communication}

Designed from a pedagogical perspective (Bébian) or more generally from a research perspective (Stokoe and derivatives), few notation systems have been intended to allow written communication. This was the intended purpose of the incomplete D'Sign system (Garcia 2000; Jouison 1990, 1995), whose originality at its outset rests in the consideration of all articulators, both manual and non-manual, on the discourse level. However, the only system designed with the dual objective of serving both for research and communication is SignWriting (1974-2011; see Sutton 1999), which can AQ344 now claim to approach the status of writing system. 
Although it is an alphabetic type of notation, like its predecessors, the significant innovation in SignWriting lies in its semiographic aspect, adding the analogical to the digital (see Fig. 72.3). This system represents all gesture production as a multi-parameter composition and as a whole (each "graphic cell" includes, analogically, the symbols of various articulators, allowing us to see a body creating a space and a gaze), thus allowing a detailed reconstruction of spatial phenomena. SignWriting was designed to evolve through use and was quickly adopted by deaf signers. It is taught at various schools around the world and supported by numerous publications using the system (see, http://www. signwriting.org/). Over the past decade, the system has been the object of detailed experiments led by the Italian deaf team directed by E. Antinoro Pizzuto (e.g. Pizzuto, Chiari, and Rossini 2008; Pizzuto et al. 2008), revealing the possibility (previously unachievable) AQ345 for a deaf speaker to accurately reconstruct discourse rich in transfer units from a text of Lingua dei Segni Italiana (Italian Sign Language) in SignWriting, whether written or transcribed (Di Renzo et al. 2006). However, limitations do remain. In the absence of spelling rules, the system often allows multiple representations for the same sign. There are also analogical setbacks - the absence of explicit and economic marking of spatial processes of anaphora - and problems of computational compatibility (see 2.2.2 below).

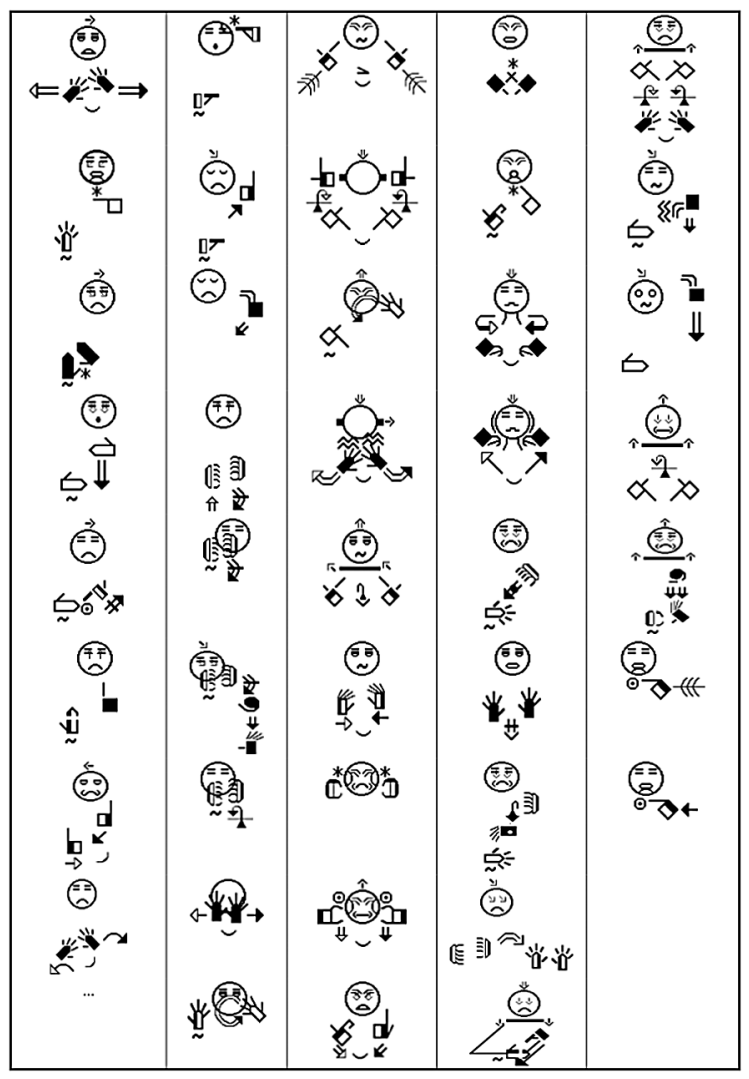

Fig. 72.3: SignWriting Transcription of the beginning of a story in LIS (Di Renzo et al. 2009). The AQ346 circled part provides a gestural unit (our "graphic cell"). The space of the cell analogically represents the signing space. 
The alternative to the various limitations posed by specific notation systems has been, and remains, the written form of the spoken language. From the very beginning of linguistic research (e.g. Stokoe 1960; Klima and Bellugi 1979), sign language researchers have resorted to graphic representations based on a "gloss," that is, the representation of isolated sign language signs (or sequences) by written words (or sequences) of the national spoken language, posed as representing the signs of the sign language studied. These gloss-based notations have undergone recent systematisation to overcome the limitations of mono-linearity.

\section{Annotation systems}

\subsection{Multi-Linear annotation}

Johnston (1991) proposes a system he calls the Interlinear System, a primary concern of which is the representation of the signifier form via HamNoSys, alongside the essential use of written English. The issue, at least initially (see Johnston 2001), was to ensure access to the data. The Interlinear System is presented as multi-linear; however, the typical relation between the lines is simple superposition, showing the same phenomena at different levels of analysis. The fields used are:

(i) a "phonetic" notation in HamNoSys (actually, a notation of the signs in the citation form, complemented, if necessary, by the spatial specifications available in HamNoSys),

(ii) facial expression,

(iii) an English gloss of conventional signs,

(iv) any signs of mouthing, and

(v) a translation in English.

Actual parametric multi-linearity affects only lines (2) and (4).

The situation is different in annotation systems based on musical score notation, which allow both horizontal and vertical reading of information. The multi-linearity of these systems is indeed semiotic, parallel lines representing the respective time frames and thus inter-relating the various (manual and non-manual) parameters. This approach is prominent among researchers who consider non-manual aspects and parametric multi-linearity as essential linguistic aspects. Such is the system developed by Baker-Shenk (1983), the first in the literature to provide a musical-score-type transcription. Cuxac $(1996,2000)$ employs the same principle, but adds two new parts, thus proposing a four-parts system:

(i) a parametric score transcription (right hand, left hand, two hands, body, face, eye gaze and facial expression),

(ii) systematic recovery of each element of the score, here numbered and explained,

(iii) a literal gloss translation in written French,

(iv) a translation in standard French.

Parts (2) and (3) are original and intended to accurately assign each annotated element to its meaning component, thus partially compensating for the loss of information of signifier forms. 
Other multi-linear systems (e.g. Boyes-Braem 2001; Fusellier-Souza 2004; Sallandre 2003) add the use of a spreadsheet, which provides several advantages: precise time coding of the annotated element, the addition of images from the video signal, referring specifically to the time code, the possibility of simple queries, and the export of information to a database. The use of spreadsheets thus enables computerised annotation and quantitative analysis of the annotated data.

\subsection{Multimedia annotation software}

A major step was taken at the turn of the millennium with the advent of multimedia annotation software. Software of this type is designed on the principle of the musical score and incorporates many additional modules. Their crucial impact is in enabling the alignment of the annotation and the video signal. Researchers can now annotate with a precision that would have been difficult if not impossible with older systems, which forced the annotator to stop watching, memorise the item under consideration, and only then to annotate. The constraining mental gymnastics involved led to the potential loss of information and increased the difficulty of interpretation.

Multimedia software, freely available online, can be divided into two categories according to their availability: precursor or confidential systems and systems in wide distribution. One of the first systems in the first category was SyncWRITER (Hanke and Prillwitz 1995), which relied on a HamNoSys grid synchronized to a video signal, AQ347 and used mostly in 1989-1992. SignStream was first used in 1999 at the University of Boston (Neidle 2001) and remains in use today (version 2.2.2). We should also mention SLAnnotation, released by the PRESTO research centre in Toulouse, France (http:// www.irit.fr/presto/resultats.html). This modest annotation tool notably allowed the addition of annotation in sign language (via a video that appears in a separate window) alongside the traditional written annotation.

The most developed systems to gradually gain ground in the scientific community are ANVIL and ELAN. In both programs, annotation files can be imported and exported using various formats (e.g. text, spreadsheet), providing flexibility and compatibility to the user. Another major advantage of these programs is the set of annotation tools available, enabling semi-automatic annotation (e.g. types of segmentation, a merge function), and tools of information retrieval (e.g. statistical tools).

ANVIL (Kipp 2001) is widely used by computer scientists in the field of sign language and linguists specializing in human gestures. ANVIL tracks enable the integration not only of text but also of icons and colours, making it attractive and a useful aid in intuitive data analysis. This software also incorporates a 3D visualization tool used for motion capture that is synchronized to the video signal and the 2D grid annotation (Kipp in press).

AQ348

Unlike ANVIL, ELAN (http://www.lat-mpi.eu/tools/elan/), developed at the Max Planck Institute for Psycholinguistics in Nijmegen (MPI), is an open source program. As such, it is regularly updated and focused on the needs of its users (Brugman and Russell 2004; Crasborn and Sloetjes 2008). Its ease of use and flexibility has made it AQ349 the dominating software in linguistic research of sign language. Some research centres have abandoned their locally-developed tool in favour of ELAN, while adapting some of its features. Thus, the Hamburg team no longer uses SyncWriter, but has integrated HamNoSys into ELAN, interfacing with their lexical database Ilex. 
ELAN is programmed in Java under $\mathrm{xml}$ and is compatible with Mac OS as well as with Windows and Linux. It is part of a set of freeware tools available on the Max Planck Institute platform (Language Archiving Technology), where it is connected, in particular, to the ARBIL tool for the precise (and almost exhaustive) administration of metadata (IMDI Metadata tools). The first step in the creation of an annotation grid, is the definition of the template (e.g. tiers, types and stereotypes, controlled vocabulary), allowing a hierarchy of information determined on the basis of the desired analysis. As shown in Fig. 72.4, the ELAN grid is organized in distinct parts: (a) the video, which progresses in sync with the other elements, (b) the annotation grid, and (c) additional textual and numerical elements. The video alignment indicator (or cursor) is symbolized by a thin vertical line in the grid (b), thus keeping track of the video reference. Once the annotation template is established, annotation can be performed simultaneously by multiple annotators, thus promoting interaction between users.

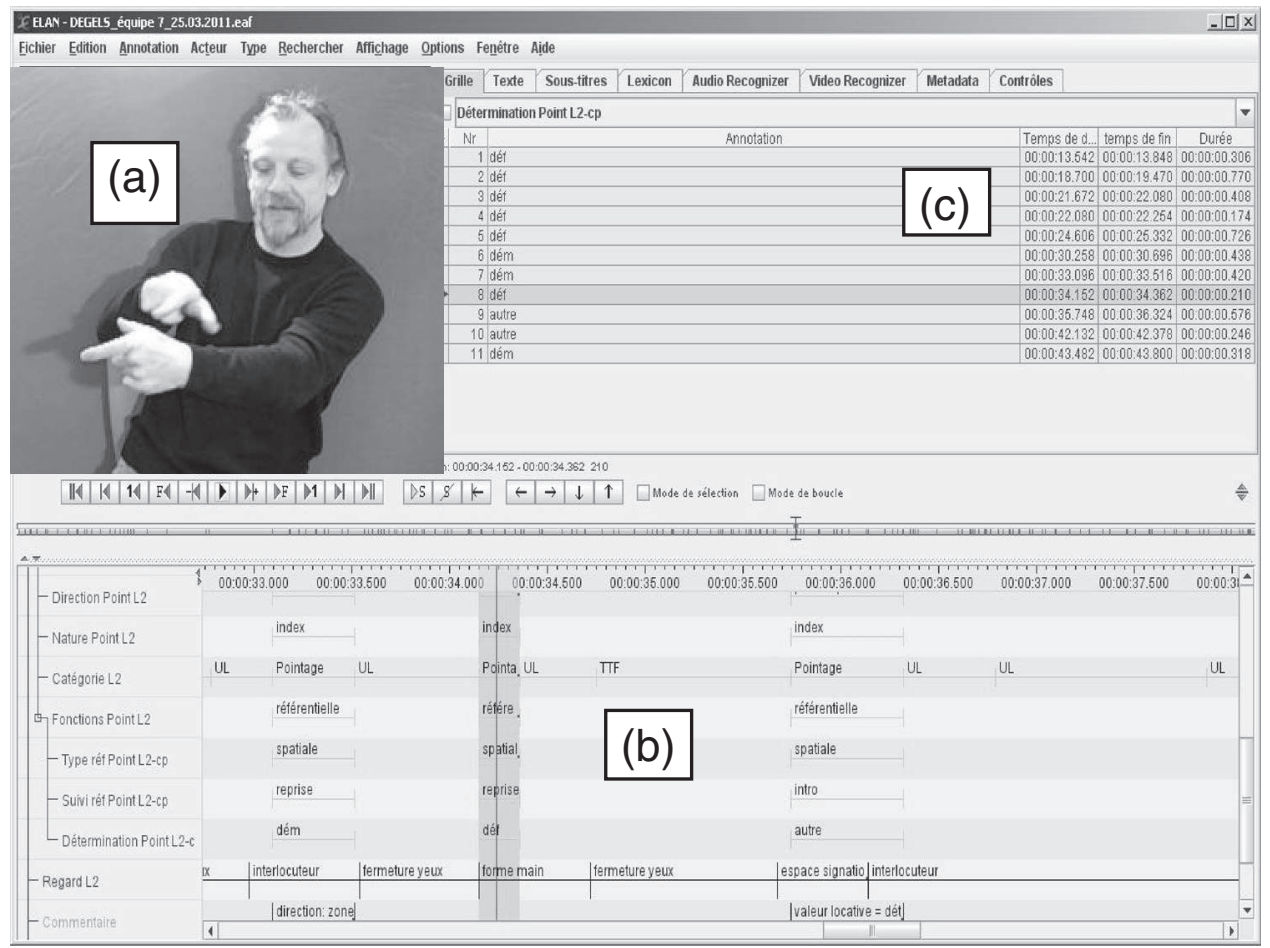

Fig. 72.4: Screen capture of annotation with ELAN (Garcia et al. 2011)

The convenience and speed of multimedia tools enable the detailed annotation of large corpora within reasonable timeframes, undoubtedly bringing a new era to sign language research. Resultant annotations become, in effect, machine-readable, enabling new and innovative types of analysis (e.g. diversification of statistical queries, lexicometry). So, the use of such software provides a real heuristic dimension, enabling new types of observation. However, these software are complex computerised tools that require regular updating and maintenance that only large research institutes can provide. 


\section{Problems and perspectives}

The five international workshops of the ESF project InterSign 1998-2000 (Bergman et al. 2001) testify to the emergent interest in the problems of discourse annotation among sign language researchers, which increases with the expansion of large sign language corpora (e.g Workshops on The Processing of Sign Languages, LREC 2004, 2006, 2008, 2010; Sign Linguistics Corpora Network 2009-2010, http://www.ru.nl/slcn/). The three key issues are the optimisation of annotation tasks, automated processing of large corpora, and the possibility of sharing corpora (both data and metadata) to enable comparisons between sign languages. The latter rests on the establishment of minimal international standards of annotation and data documentation. In addition to the technological aspects and the classic disagreements related to the choice of theoretical models and diverse research interests, much of the current difficulties are due to the absence of a notation system of sign language, in the strict sense, and (therefore) to the fact that the basic medium of annotation remains written form of national spoken languages.

\subsection{The major disadvantages with the use of written words of spoken languages}

Difficulties associated with the very diversity of the spoken languages used for this purpose are coupled with the semiotic heterogeneity of the use of a spoken language written form and the almost total absence of standardised practices, even in the same country. Thus, writing can be used in the same annotation to describe both the signifier form ("gaze towards the addressee"), its sense ("interrogative mimicry") or to provide grammatical information (e.g Cl. for "classifier"), the latter potentially using abbreviated forms (e.g. NS for "name signs," and DV for "depicting verbs," in Chen Pichler et al. 2010).

However, the key issue is the external segmentation induced by the use of a written language. Regardless of the typological gap between spoken language and sign language in general, each sign language has its own organization, like any other language, which may not correspond to the words and units of the spoken language of the same region. Thus, the use of spoken/written language increases the risk of affecting the analysis, given that a written word often carries morphosyntactic information (category, grammatical inflection) which it superimposes on the annotated unit. The linguist can, of course, conventionalise the use of label-words (e.g. following the standards of spoken language research, establishing masculine singular nouns and infinitive verbs as default non-inflected forms), or pose the use of gloss-words as referring to the signifier form only, without aiming to indicate meaning or discourse function in this way (Cuxac 2000). However, and this is even more significant in long corpora, this practice necessarily presents a biased image of sign language and does not resolve the potential risk of bias on analysis (on these points, see Pizzuto and Pietrandrea 2001; Di Renzo et al. 2009).

But there is more. The risk of segmenting sign language units through the structures of the annotating spoken language is often downplayed by sign language linguists who believe that the basic units of sign languages are conventional lexical signs, not much distinct from the lexemes of spoken language. However, in an approach that considers transfer units as central (see section 2.1), this becomes a considerable difficulty, since 
transfer units are, at best, equivalent to a clause in spoken language (e.g. "the thin elongated vertical shape moves slowly towards a fixed horizontal oval shape"). Whatever the theoretical status granted to such units, no sign language linguist can now deny their massive presence in discourse (e.g. Emmorey 2003; Liddell 2003). The problem of their graphical representation and the inadequacy of spoken language glosses for such purposes are thus unavoidable. Ultimately, for Pizzuto, Rossini, and Russo (2006), Garcia (2006, 2010), and Antinoro Pizzuto et al. (in preparation), these prob- AQ351 lems are epistemological. Pizzuto and Pietrandrea (2001) have stressed that the socalled "gloss" or "annotation" of sign language cannot claim this status in the sense it has in spoken language research, to the extent (and quasi-systematically from now on) that it lacks the initial level of transcribing the signifier form. This is not a problem in the annotation of any spoken language, even ones without their own writing system, since spoken languages can always be phonetically transcribed using the international phonetic alphabet. The video clip incorporated into the so-called annotation software (see section 3.2.2) is not a functional equivalent, and even less so, given that the sign language signal corresponds to highly multi-linear signifiers.

The Berkeley Transcription System (BTS), proposed by Slobin's and Hoiting's team (Hoiting and Slobin 2002; Slobin et al. 2001), was explicitly developed to find alternatives to sign language's glossing problems. It is based on allowing a graphical (mono-linear) symbolisation, not on the level of the sign but of the morpheme, lexical as well as grammatical. Originally designed for the transcription of American Sign Language and Sign Language of the Netherlands (NGT), the Berkeley Transcription System, which is connected to the CHILDES system (MacWhinney 2000), allows the transcription of any sign language. However, its primary medium remains written English, although supplemented by all available graphical resources (e.g. typographical variants, arrows, brackets, figures), in rigorously standardised uses. Indeed, this system simply transfers the limitations of glossing to the sub-lexical level. Another problem, aside from its low readability, is the rigidity introduced by the labelling system provided, which is based on specific theoretical assumptions that are not necessarily shared.

For Johnston (1991, 2001, 2008), the only real issue is a consistent use of glossing. This requires lemmatisation of the lexicon of studied sign language, which is posited as essential to any "modern corpus" (i.e. machine-readable) and requires the formation, prior to any annotation, of a lexical database consisting of the systematic assignment of ID-glosses to these lemmas, to be enhanced and revised later, following the analysis of large corpora (see Auslan database). While such a lexical database undoubtedly provides internal glossing consistency, its constituents may be subject to debate (the criteria for defining the lexical unit and predetermination of the lemma and its variants prior to discourse analysis, see Konrad 2011). The underlying focus on conventional signs alone cannot resolve the issue of the annotation of transfer units, let alone the problem of their representation.

\subsection{Perspectives}

On the technical level, we can expect much faster progress in the field of image analysis and automatic recognition, and in development of tools of video inlay and segmentation (Braffort and Dalle 2008; Collet, Gonzalez, and Milachon 2010). However, two main 
types of advances are necessary if we are to resolve the problems posed by the current annotation practices of sign language corpora.

First, while the internal consistency of annotations is, naturally, a prerequisite for any productive and significant automatic processing of corpora, lemmatisation, which is equally necessary, must take into account non-conventional units and their components, which form $30-80 \%$ of these corpora. Cuxac's (2000) hypothesis of a morphemic compositionality, many components of which are shared by both conventional units and transfer units, seems to open a promising alternative route for the creation of lexical databases that are more faithful to the structures of sign language (Garcia 2006, 2010).

At the same time, progress is needed in the development and/or improvement of notation systems that allow analytical representation of the signifier form in discourse, which remains the only way to allow rigorous elaboration of the annotations linked to the signal itself. On this point, we believe that much can be expected from the continuation of experiments on SignWriting noted above (see Bianchini et al. 2011) and from current efforts to integrate it into annotation software (e.g. Antinoro Pizzuto et al. in preparation).

AQ352

\section{References}

Antinoro Pizzuto, Elena, Isabella Chiari and Paolo Rossini 2008. The representation issue and its AQ353 multifaceted aspects in constructing sign language corpora: Questions, answers, further problems. In: Nicoletta Calzolari, Khalid Choukri, Bente Maegaard, Joseph Mariani, Jan Odjik, Stelios Piperidis and Daniel Tapias (eds.), Proceedings of LREC 2008, Sixth International Conference on Language Resources and Evaluation, 150-158. Paris: European Language Resources Association.

Antinoro Pizzuto, Elena, Brigitte Garcia, Paolo Rossini, Claudia S. Bianchini and Christian Cuxac in preparation. Annotation tools for sign language (SL): The nodal problem of the graphical representation of forms. In: Terry Janzen and Sherman Wilcox (eds.), Cognitive Approaches to Signed Language Research. Berlin: De Gruyter Mouton.

Antinoro Pizzuto, Elena, Paolo Rossini, Marie-Anne Sallandre and Erin Wilkinson 2008. Deixis, anaphora and highly iconic structures: Cross-linguistic evidence on American (ASL), French (LSF) and Italian (LIS) Signed Languages. In: Ronice Müller de Quadros (ed.), Proceedings of TISLR9, Theoretical Issues in Sign Language Research Conference, 475-495. Petrópolis, RJ: Editora Arara Azul.

Baker-Shenk, Charlotte 1983. Nonmanual behaviors in sign languages: Methodological concerns and recent findings. In: William Stokoe and Virginia Volterra (eds.), Sign Language Research, 175-184. Burtonsville: Linstock Press.

Battison, Robbin 1973. Phonology in American Sign Language: 3-D and digitvision. Paper presented at the California Linguistic Association Conference, Stanford, CA.

Bébian, Auguste 1825. Mimographie, ou Essai d'Écriture Mimique, Propre à Régulariser le Langage des Sourds-Muets. Paris: Louis Colas.

Bentele, Susan 1999. HamNoSys. Sample of sentences from Goldilocks. http://www.signwriting. org/forums/linguistics/ling007.html.

Bergman, Brita, Penny Boyes-Braem, Thomas Hanke and Elena Pizzuto (eds.) 2001. Sign Transcription and Database Storage of Sign Information, special issue of Sign Language and Linguistics 4(1/2). Amsterdam: John Benjamins.

Bianchini, Claudia S., Gabriele Gianfreda, Alessio di Renzo, Tommaso Lucioli, Giulia Petitta, Barbara Pennacchi, Luca Lamano and Paolo Rossini 2011. Ecrire une langue sans forme écrite: 
Réflexions sur l'écriture et la transcription de la Langue des Signes Italienne (LIS). In: Gilles Col and Sylvester N. Osu (eds.), Transcrire, écrire, formaliser, 1. Traveaux Linguistiques CerLiCO, 71-89. Rennes, France: Presses Universitaires de Rennes.

Bonnal, Françoise 2005. Sémiogenèse de la langue des signes française: étude critique des signes attestés sur support papier depuis le XVIIIe siècle et nouvelles perspectives de dictionnaires. Ph.D. dissertation, University of Toulouse Le Mirail, France.

Boutora, Leila 2005. Bibliographie sur les formes graphiques des langues des signes. Projet RIAM-ANR LS Script, 25 pages. http://lpl-aix.fr/ fulltext/4786.pdf.

Boyes-Braem, Penny 2001. Sign language text transcription and analyses using 'Microsoft Excel.' In: Brita Bergman, Penny Boyes-Braem, Thomas Hanke and Elena Antinoro Pizzuto (eds.), Sign Transcription and Database Storage of Sign Information, special issue of Sign Language and Linguistics 4(1/2): 241-250. Amsterdam: John Benjamins.

Braffort, Annelies and Patrice Dalle 2008. Sign language applications: Preliminary modelling. Universal Access in the Information Society, special issue 6/4: 393-404. Berlin: Springer.

Brennan, Mary 1990. Productive morphology in British Sign Language. In: Siegmund Prillwitz and Tomas Vollhaber (eds.), Proceedings of the International Congress on Sign Language Research and Application, Hamburg'90, 205-228. Hamburg: Signum.

Brugman, Hennie and Albert Russel 2004. Annotating multimedia/multi-modal resources with ELAN. In: Maria Teresa Lino, Maria Francisca Xavier, Fátima Ferreira, Rute Costa and Raquel Silva, with the collaboration of Carla Pereira, Filipa Carvalho, Milene Lopes, Mónica Catarino and Sérgio Barros (eds.), Proceedings of LREC 2004, Fourth International Conference on Language Resources and Evaluation, 2065-2068. Paris: European Language Resources Association.

Chen Pichler, Deborah, Julie A. Hochgesang, Diane Lillo-Martin and Ronice Muller de Quadros 2010. Conventions for sign and speech transcription of child bimodal bilingual corpora in ELAN. Langage Interaction Acquisition 1(1): 11-40. Amsterdam/Philadelphia: John Benjamins.

Collet, Christophe, Matilde Gonzalez and Fabien Milachon 2010. Distributed system architecture for assisted annotation of video corpora. In: Nicoletta Calzolari, Khalid Choukri, Bente Maegaard, Joseph Mariani, Jan Odjik, Stelios Piperidis and Daniel Tapias (eds.), Proceedings of LREC 2008, Sixth International Conference on Language Resources and Evaluation, 49-52. Paris: European Language Resources Association.

Crasborn, Onno and Han Sloetjes 2008. Enhanced ELAN functionality for sign language corpora. In: Nicoletta Calzolari, Khalid Choukri, Bente Maegaard, Joseph Mariani, Jan Odjik, Stelios Piperidis and Daniel Tapias (eds.), Proceedings of LREC 2008, Sixth International Conference on Language Resources and Evaluation, 39-43. Paris: European Language Resources Association.

Cuxac, Christian 1996. Fonctions et structures de l'iconicité dans les langues des signes. Thèse de Doctorat d'Etat, Paris 5 University.

Cuxac, Christian 2000. La Langue des Signes Française (LSF). Les Voies de l'Iconicité. Faits de Langue, Paris: Ophrys.

Di Renzo, Alessio, Luca Lamano, Tommaso Lucioli, Barbara Pennachi and Luca Ponzo 2006. Italian Sign Language: Can we write it and transcribe it with Sign Writing? In: Proceedings of LREC 2006, Fifth International Conference on Language Resources and Evaluation, 11-16. Genova, Italy.

Emmorey, Karen (ed.) 2003. Perspectives on Classifier Constructions in Sign Languages. Mahwah, NJ: Lawrence Erlbaum.

Fischer, Renate 1995. The notation of sign languages: Bébian's Mimographie. In: Heleen F. Bos and Gertrude M. Schermer (eds), Sign Language Research 1994, Proceedings of the Fourth European Congress on Sign Language Research, 285-302. (International Studies on Sign Language and Communication of the Deaf 29.) Hamburg, Germany: Signum.

Fusellier-Souza, Ivani 2004. Sémiogenèse des Langues des Signes. Étude de langues des signes primaires (LSP) pratiquées par des sourds brésiliens. Ph.D. dissertation, Paris 8 University. 
Garcia, Brigitte 2000. Contribution à l'histoire des débuts de la recherche linguistique sur la Langue des Signes Française (LSF); les travaux de Paul Jouison. Ph.D. dissertation, Paris 5 University.

Garcia, Brigitte 2006. The methodological, linguistic and semiological bases for the elaboration of a written form of LSF (French Sign Language). In: Proceedings of LREC 2006, Fifth International Conference on Language Resources and Evaluation, 31-36. Genova, Italy.

Garcia, Brigitte 2010. Sourds, surdité, langue(s) des signes et épistémologie des sciences du langage. Problématiques de la scripturisation et modélisation des bas niveaux en Langue des Signes Française (LSF). Thèse d'Habilitation à Diriger les Recherches, Paris 8 University.

Garcia, Brigitte, Marie-Anne Sallandre, Camille Schoder and Marie-Thérèse L'Huillier 2011. Typologie des pointages en Langue des Signes Française (LSF) et problématiques de leur annotation. In: Proceedings of TALN Conference 2011, 107-119. Montpellier, France.

Hanke, Thomas and Siegmund Prillwitz 1995. SyncWRITER. Integrating video into the transcription and analysis of sign language. In: Trude Schermer and Heleen Bos (eds.), Proceedings of the Fourth European Congress on Sign Language Research, 303-312. (International Studies on Sign Language and Communication of the Deaf 29.) Hamburg, Germany: Signum.

Hanke, Thomas and Jakob Storz 2008. Ilex - a database tool for integrating sign language corpus linguistics and sign language lexicography. In: Nicoletta Calzolari, Khalid Choukri, Bente Maegaard, Joseph Mariani, Jan Odjik, Stelios Piperidis and Daniel Tapias (eds.), Proceedings of LREC 2008, Sixth International Conference on Language Resources and Evaluation, 64-67. Paris: European Language Resources Association.

Hoiting, Nini and Dan Slobin 2002. Transcription as a tool for understanding: The Berkeley Transcription System for sign language research (BTS). In: Gary Morgan and Bencie Woll (eds.), Directions in Sign Language Acquisition, 55-75. Amsterdam: John Benjamins.

Johnston, Trevor 1991. Transcription and glossing of sign language texts: Examples from Auslan (Australian Sign Language). International Journal of Sign Linguistics 2(1): 3-28.

Johnston, Trevor 2001. The lexical database of Auslan (Australian Sign Language). In: Ronnie Wilbur (ed.), Sign Language and Linguistics 4(1/2): 145-169. Amsterdam/Philadelphia: John Benjamins.

Johnston, Trevor 2008. Corpus linguistics and signed languages: No lemmata, no corpus. In: Nicoletta Calzolari, Khalid Choukri, Bente Maegaard, Joseph Mariani, Jan Odjik, Stelios Piperidis and Daniel Tapias (eds.), Proceedings of LREC 2008, Sixth International Conference on Language Resources and Evaluation, 82-87. Paris: European Language Resources Association.

Jouison, Paul 1990. Analysis and linear transcription of sign language discourse. In: Siegmund Prillwitz and Tomas Vollhaber (eds.), Proceedings of the International Congress on Sign Language Research and Application, Hamburg'90, 337-354. Hamburg, Germany: Signum.

Jouison, Paul 1995. Ecrits sur la Langue des Signes Française (LSF). Edition critique établie par Brigitte Garcia. Paris: L'Harmattan.

Kipp, Michael 2001. Anvil - a generic annotation tool for multimodal dialogue. In: Proceedings of the Seventh European Conference on Speech Communication and Technology (Eurospeech), 1367-1370. Aalborg, Denmark.

Kipp, Michael in press. Multimedia annotation, querying and analysis in ANVIL. In: Mark T. AQ367 Maybury (ed.), Multimedia Information Extraction, Chapter 19. IEEE Computer Society Press.

Klima, Edouard S. and Ursula Bellugi 1979. The Signs of Language. Cambridge, MA: Harvard University Press.

Konrad, Reiner 2011. Die Lexikalische Struktur der Deutschen Gebärdensprache im Spiegel Empirischer Fachgebärdenlexikographie. Zur Integration der Ikonizität in ein Korpusbasiertes Lexikonmodell. Tübingen, Germany: Narr.

Liddell, Scott K. 2003 Grammar, Gesture, and Meaning in American Sign Language. Cambridge: Cambridge University Press.

MacWhinney, Brian 2000. The CHILDES Project: Tools for Analyzing Talk. Mahwah, NJ: Lawrence Erlbaum.

Martin, Joe 2000. A linguistic comparison. The notation systems for signed languages: Stokoe Notation and Sutton SignWriting. http://www.signwriting.org/forums/linguistics/ling016.html. 
Miller, Christopher [1994] 2001. Some reflections on the need for a common sign notation. In: Brita Bergman, Penny Boyes-Braem, Thomas Hanke and Elena Pizzuto (eds.), Sign Transcription and Database Storage of Sign Information, special issue of Sign Language and Linguistics 4 (1/2): 11-28. Amsterdam: John Benjamins.

Montaigne, Michel de 2009. Les Essais. Paris: Gallimard.

Neidle, Carol 2001. SignStream ${ }^{\mathrm{TM}}$ : A database tool for research on visual-gestural language. In: Brita Bergman, Penny Boyes-Braem, Thomas Hanke and Elena Pizzuto (eds.), Sign Transcription and Database Storage of Sign Information, special issue of Sign Language and Linguistics 4 (1/2): 203-214. Amsterdam: John Benjamins.

Piroux, Joseph 1830. Le Vocabulaire des Sourds-Muets (Partie Iconographique). Nancy, France: Grimblot.

Pizzuto, Elena and Paola Pietrandrea 2001. The notation of signed texts: Open questions and indications for further research. In: Brita Bergman, Penny Boyes-Braem, Thomas Hanke and Elena Pizzuto (eds.), Sign Transcription and Database Storage of Sign Information, special issue of Sign Language and Linguistics 4(1/2): 29-45. Amsterdam: John Benjamins.

Pizzuto, Elena, Paolo Rossini and Tomasso Russo 2006. Representing signed languages in written form: Questions that need to be posed. In: Proceedings of LREC 2006, Fifth International Conference on Language Resources and Evaluation, 1-6. Genova, Italy.

AQ368

Prillwitz, Siegmund, Regina Leven, Heiko Zienert, Thomas Hanke and Jan Henning 1989. Hamburg Notation System for Sign Languages. An Introductory Guide, HamNoSys Version 2.0. Hamburg, Germany: Signum Press.

Saint-Augustin 2002. Le Maître. Traduction, présentation et notes de Bernard Jolibert, 2ème édition revue et corrigée. Paris: Klincksieck.

Sallandre, Marie-Anne 2003. Les unités du discours en Langue des Signes Française. Tentative de catégorisation dans le cadre d'une grammaire de l'iconicité. Ph.D. dissertation, Paris 8 Université.

Slobin, Dan I., Nini Hoiting, Michelle Anthony, Yael Biederman, Marlon Kuntze, Reyna Lindert, Jennie Pyers, Helen Thumann and Amy Weinberg 2001. Sign language transcription at the level of meaning components: The Berkeley Transcription System (BTS). In: Brita Bergman, Penny Boyes-Braem, Thomas Hanke and Elena Pizzuto (eds.), Sign Transcription and Database Storage of Sign Information, special issue of Sign Language and Linguistics 4(1/2): 63104. Amsterdam: John Benjamins.

Stokoe, William C. 1960. Sign language structure. Studies in Linguistics - Occasional Papers 8. Buffalo, NY: Department of Anthropology and Linguistics, University of Buffalo. (Revised edition Silver Spring, MD: Linstock Press [1978]).

Stokoe, William C. 1987. Sign writing systems. In: John V. van Cleve (ed.), Gallaudet Encyclopedia of Deaf People and Deafness, Volume 3, 118-120. New York: McGraw-Hill.

Stokoe, William C., Dorothy Casterline and Carl Croneberg [1965] 1976. A Dictionary of American Sign Language on Linguistic Principles. Washington, DC: Gallaudet College.

Sutton, Valerie [1995] 1999. Lessons in SignWriting. Textbook and Workbook. La Jolla, CA: Deaf Action Commitee for Sign Writing. [First published 1995]

Brigitte Garcia, Paris (France)

Marie-Anne Sallandre, Paris (France) 